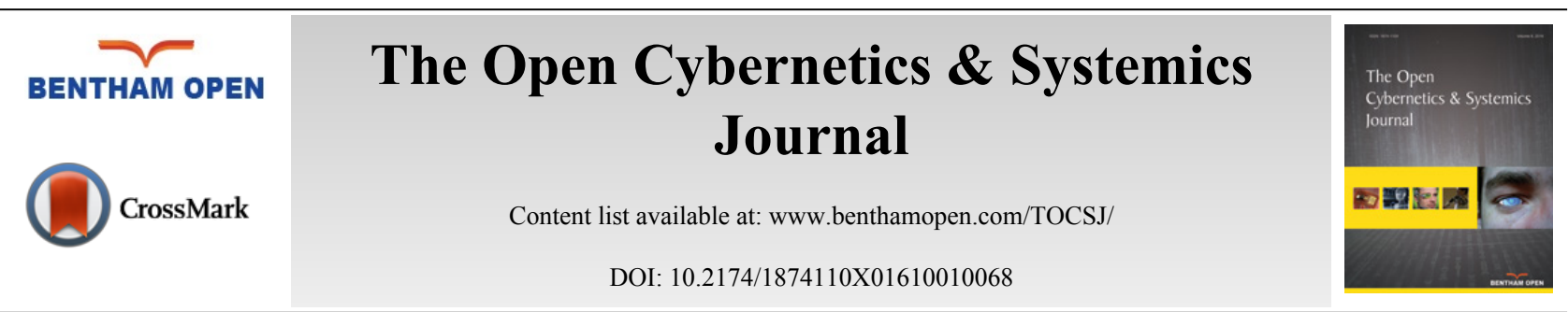

\title{
Retraction Notice: Coupled Model and Algorithm of Spatial Partition Based on Multiple- Factor
}

Jiang Hai-Dong ${ }^{1}$, Tianwei Chen ${ }^{2, *}$ and Zhang Ke-Neng ${ }^{1}$

${ }^{I}$ School of Geosciences and Info-Physics, Central South University, Changsha, Hunan, 410083, P.R. China

${ }^{2}$ College of Geomatics and Geoinformation, Guilin University of Technology, Guilin, Guangxi, 541004, P.R. China

\section{RETRACTION}

The Publisher and Editor have retracted this article [1] in accordance with good ethical practices. After thorough investigations we believe that the peer review process was compromised. The article was published online on 31-07-2015.

\section{REFERENCE}

[1] J. Hai-Dong, T. Chen, and Z. Ke-Neng, "Coupled Model and Algorithm of Spatial Partition Based on Multiple- Factor", Open Cybern. Syst. $J$. , vol. 9, pp. 786-791, 2015.

(C) Hai-Dong et al.; Licensee Bentham Open.

This is an open access article licensed under the terms of the Creative Commons Attribution-Non-Commercial 4.0 International Public License (CC BY-NC 4.0) (https://creativecommons.org/licenses/by-nc/4.0/legalcode), which permits unrestricted, non-commercial use, distribution and reproduction in any medium, provided the work is properly cited.

\footnotetext{
* Address correspondence to this author at the College of Geomatics and Geoinformation, Guilin University of Technology, Guilin, Guangxi, 541004, P.R. China; Tel: 18978335405; E-mail: ctw@glut.edu.cn
} 